\title{
ESTUDO DA CONTAMINAÇÃO POR ENTEROPARASITAS EM HORTALIÇAS COMERCIALIZADAS NOS SUPERMERCADOS DA CIDADE DO RIO DE JANEIRO
}

\author{
Joaquim Pereira da Silva, Mauro Célio de Almeida Marzochi, Léa \\ Camillo-Coura, Adriana de Almeida Messias e Sebastiana Marques
}

\begin{abstract}
Através de métodos parasitológicos usuais avaliou-se a contaminação por cistos e ovos de enteroparasitas de 220 amostras de bortaliças que são consumidas cruas e comercializadas nas zonas norte (de menor poder aquisitivo) e sul (de maior poder aquisitivo) da Cidade do Rio de Janeiro. Apesar de não ter bavido aparente diferença na procedência das bortaliças avaliadas, constatou-se maior grau de contaminação nas amostras procedentes da zona norte e nas amostras de alface (Lactuca sativa). Discutiu-se a possibilidade de a diferença observada estar relacionada ao acondicionamento das bortaliças ou ser devido à manipulação das mesmas por vendedores e consumidores.
\end{abstract}

Palavras-chaves : Parasitas intestinais. Hortaliças. Contaminação.

As parasitoses intestinais, pela sua elevada prevalência e pela diversidade de manifestaçôes clínicas, representam um problema de grande importância en Saúde Pública, particularmente em países em desenvolvimento, onde ainda são insatisfatórias as condições de saneamento e de educação das populações, especialmente, das classes sociais menos favorecidas. Os alimentos consumidos crus e contaminados pelo meio ambiente e por manipuladores infectados contribuem para formar a cadeia de transmissão destas parasitoses, sendo este fator considerado como um dos mais importantes meios de disseminação.

Os fatores que concorrem para a ocorrência de doenças parasitárias através da ingestão de frutas e verduras consumidas cruas, oriundas de áreas cultivadas contaminadas por dejetos fecais ou irrigadas com águas poluídas, têm despertado o interesse de pesquisadores de várias partes do mundo ${ }^{1112131821}$, assim como no Brasil ${ }^{2467891016}$ 171920

Considerando-se a gravidade das doenças bacterianas, virais e parasitárias, cujos agentes

Departamento de Ciências Biológicas, Escola Nacional de Saúde Pública da Fundação Oswaldo Cruz, Rio de Janeiro, RJ.

Endereço para correspondência: $\mathrm{Dr}^{\mathrm{R}}$ Léa Camillo-Coura. $\mathrm{R}$ Lcopoldo Bulhões 1480 - $6^{\circ}$ andar, 21041-210, Rio de Janeiro, RJ. Fax (021) 280-8194.

Recebido para publicação em 11/04/94. são eliminados pelas fezes humanas, impõe-se a necessidade de adoção de métodos práticos, répidos e sensíveis de monitoramento da poluição fecal do ambiente. A evidenciação e a identificação dos cistos e ovos dos enteroparasitas humanos no meio ambiente constitui um importante indicador de contaminação fecal do mesmo, sendo mais simples e rápido que $o$ isolamento $e$ identificação de bactérias e virus.

Propõe-se, neste trabalho, monitorar a contaminação fecal ambiental através da pesquisa de cistos de protozoários e ovos de helmintos em hortaliças que são consumidas cruas, comercializadas em supermercados que abastecem a cidade do Rio de Janeiro.

\section{MATERIAL E MÉTODOS}

Selecionaram-se vinte supermercados que recebem hortaliças diretamente da Central de Abastecimento do Estado do Rio de Janeiro (CEASA) e distribuídos em vários bairros entre zonas sul e norte da cidade. As coletas de hortaliças foram realizadas no períodos de fevereiro de 1991 e dezembro de 1992 na própria CEASA e nos supermercados selecionados alternando-se mês a mês, conforme a região. $\mathrm{Na}$ zona norte, foram coletadas 110 amostras nos seguintes bairros: Penha, Madureira, Vaz Lobo, Irajá, Bonsucesso, Vicente de Carvalho, Campo Grande, Realengo, Meier e Piedade, nos meses 
Silva JP, Marzochi MCA, Camillo-Coura $L$, Messias AA, Marques S. Estudo da contaminação por enteroparasitas em bortaliças comercializadas nos supermercados da cidade do Rio de Janeiro. Revista da Sociedade Brasileira de Medicina Tropical 28:237-241, jul-set, 1995.

de janeiro, março, maio, julho, setembro e novembro. $\mathrm{Na}$ zona sul, foram coletadas 110 amostras em Laranjeiras, Largo do Machado, Catete, Flamengo, Glória, Lapa, Botafogo, Urca, Leme e Copacabana, nos meses de fevereiro, abril, junho, agosto, outubro e dezembro.

Portanto, foram realizadas 220 coletas em supermercados, de acordo com o cronograma além de 40 diretamente dos depósitos da CEASA no mesmo período.

As hortaliças por nós selecionadas foram: alface (Lactuca sativa), agrião (Nasturtium officinale), cebolinha (Allium fistolosus) e salsa (Petroselinum sativa), procedentes de diversas localidades do Rio de Janeiro (Sumidouro, Petrópolis, Barra Mansa, Teresópolis, Itaguaí e Miguel Pereira) e de São Paulo (Birituba Mirim e Guarulhos).

Para a coleta do material, utilizaram-se sacos plásticos estéreis (devidamente fechados e etiquetados) para transporte ao laboratório e fichas de registros para anotações da procedência, espécie de verdura, data etc.

As amostras de hortaliças chegadas ao laboratório foram desfolhadas e submetidas à lavagem manual em água destilada, num recipiente apropriado, desprezando-se as folhas.

Coletava-se a água da lavagem, que era filtrada em gaze dobrada em copos cônicos para sedimentação espontânea ${ }^{3}$ por 2 horas e com o auxílio de uma pipeta graduada de $1 \mathrm{ml}$, pipetava-se aproximadamente $0,1 \mathrm{ml}$ do sedimento, $o$ qual era posteriormente examinado ao microscópio entre lamínula $(24 \times 24 \mathrm{~mm})$.

O restante do sedimento (cerca de $2 \mathrm{ml}$ ) era distribuído em duas partes: $1 \mathrm{ml}$ para tubos de centrifugação, submetido ao método de centrífugo-flutuação com sulfato de zinco. A outra parte do sedimento $(1 \mathrm{ml})$ foi suspensa em solução de bicromato de sódio $(\mathrm{d}=1,350)$ para recuperação dos ovos de helmintos.

Semeou-se o material em que houve caso de positividade para amebas em meio de cultura de Pavlova modificado. Após o crescimento no meio a $37^{\circ} \mathrm{C}$, as amebas foram coradas pela hematoxilina férrica para identificação específica.

\section{RESULTADOS}

Das 220 amostras examinadas procedentes de supermercados, $47(21,4 \%)$ encontravam-se contaminadas com ovos de helmintos e cistos de protozoários, distribuídos de acordo com as Figuras 1 e 2 e Tabela 1.

Em 40 amostras coletadas diretamente da CEASA, no mesmo período, encontramos apenas amebas de vida livre.

Não nos foi possível examinar as hortaliças de acordo com a localidade de crigem de cada

Tabela 1 - Enteroparasitas encontrados em 220 amostras de bortalicas de Supermercados do Rio de Janeiro.

\begin{tabular}{lcccccc}
\hline \multirow{2}{*}{ Agentes etiológicos } & \multicolumn{3}{c}{ Procedência } & \multicolumn{2}{c}{ Total } \\
\cline { 2 - 7 } & $\mathrm{n}^{\mathrm{o}}$ Zositivos & $(\%)$ & $\mathrm{n}^{\mathrm{o}}$ positivos & $(\%)$ & $\mathrm{n}^{\mathrm{o}}$ & $(\%)$ \\
\hline Ascaris lumbricoides & 13 & 6,0 & 3 & 1,3 & 16 & 7,3 \\
Giardia lamblia & 7 & 3,1 & 2 & 1,0 & 9 & 4,1 \\
Entamoeba coli & 5 & 2,2 & 3 & 1,3 & 8 & 3,5 \\
Enterobius vermicularis & 4 & 1,8 & 2 & 1,0 & 6 & 2,8 \\
Trichuris trichiura & 5 & 2,2 & - & & 5 & 2,2 \\
Hymenolepis diminuta & 1 & 0,5 & - & & 1 & 0,5 \\
Tricbosomoides crassicauda & 1 & 0,5 & - & & 1 & 0,5 \\
Taenia sp & 1 & 0,5 & - & & 1 & 0,5 \\
Total & 37 & 16,8 & 10 & 4,6 & 47 & 21,4 \\
\hline
\end{tabular}

uma por existirem apenas áreas destinadas para o armazenamento de cada espécie, não importando a procedência.

Nota-se a predominância de ovos de Ascaris lumbricoides (7,3\%), seguido de cistos de Giardia lamblia (4,1\%), Entamoeba coli $(3,5 \%)$, ovos de Enterobius vermicularis $(2,8 \%)$, Tricburis tricbiura $(2,2 \%)$, Trichosomoides crassicauda $(0,5 \%)$, Hymenolepis diminuta $(0,5 \%)$ e Taenia sp 
Silva JP, Marzochi MCA, Camillo-Coura L, Messias AA, Marques S. Estudo da contaminação por enteroparasitas em hortaliças comercializadas nos supermercados da cidade do Rio de Janeiro. Revista da Sociedade Brasileira de Medicina Tropical 28:237-241, jul-set, 1995.

$(0,5 \%)$. No geral, houve um predomínio de ovos de helmintos em relação à freqüência de cistos de protozoários encontrados.

Os resultados obtidos nas hortaliças revelam alto índice de contaminação por ovos de helmintos e cistos de protozoários, mais freqüente na alface (Lactuca nativa), seguida pelo agrião (Nasturtium officinale) e outros.

Os dados apresentados das zonas norte $e$ sul permitem observar maior freqüência de ovos e cistos de enteroparasitos nas zonas norte $(16,8 \%)$ quando comparada com a zona sul $(4,6 \%)$.

Também não foi possivel identificar os ovos de ancilostomídeos e larvas devido à grande quantidade de ovos e larvas de nematódeos de vida livre, presente nas amostras.

As amebas e flagelados encontrados foram examinadas morfologicamente, constatando-se que eram apenas microorganismos de vida livre habitantes do solo e água.

Não julgamos necessário fazer comparação de métodos por considerarmos que os métodos adotados são suficientes para essa finalidade. Também não abordamos o aspecto quantitativo por limitação metodológica e pelo fato de que o nosso objetivo foi a adoção de métodos práticos e rápidos.

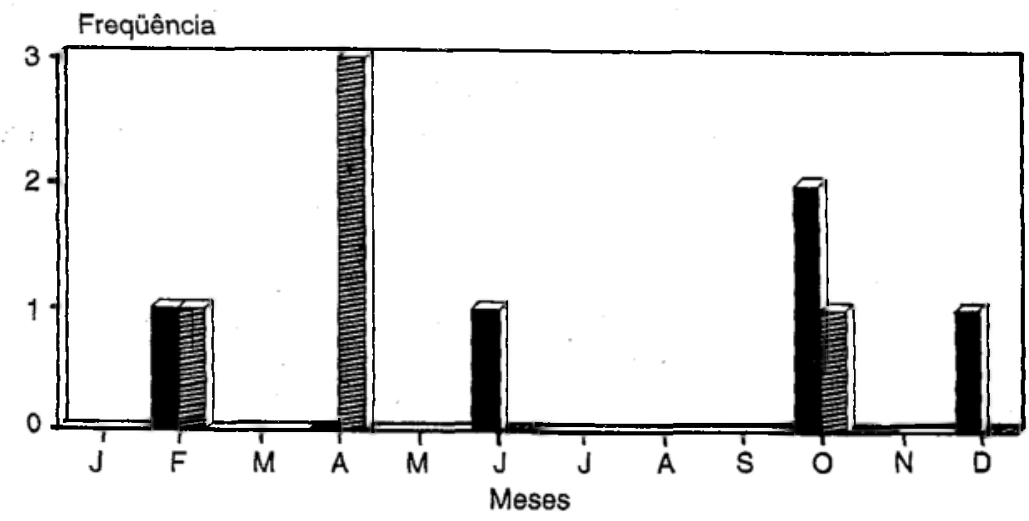

Helmintos Protozoários

Figura 1 - Frequência acumulada mensal de enteroparasitas encontrados em verduras de supermercados na zona sul nos anos de 1991 e 1992.



Helmintos Protozoários

Figura 2 - Freqüência acumulada mensal de enteroparasitas encontrados em verduras de supermercados na zona norte nos anos de 1991 e 1992. 
Silva JP, Marzochi MCA, Camillo-Coura L, Messias AA, Marques S. Estudo da contaminação por enteroparasitas em bortaliças comercializadas nos supermercados da cidade do Rto de Janeiro. Revista da Sociedade Brasileira de Medicina Tropical 28:237-241, jul-set, 1995.

\section{DISCUSSÃO}

Pretende-se fazer uma avaliação da contaminação fecal de hortaliças comercializadas em supermercados e na CEASA da Cidade do Rio de Janeiro, através de pesquisa de ovos de helmintos e cistos de protozoários.

A metodologia utilizada permite contribuir para o monitoramento da contaminação fecal de hortaliças comercializadas em supermercados que abastecem a Cidade do Rio de Janeiro. Por outro lado, outros fatores epidemiológicos tais como as moscas e a própria água contaminada utilizada na irrigação ${ }^{13}$ podem contribuir fortemente para a contaminação das verduras consumidas cruas ${ }^{7}$.

O problema da veiculação dos enteroparasitos em nossso país permanece relevante como mostram os resultados da pesquisa realizada, pois $21,4 \%$ das amostras coletadas de supermercados estavam contaminadas com ovos e cistos de enteroparasitas. Os resultados negativos encontrados nas 40 hortaliças da CEASA sugerem que a contaminação das verduras dos supermercados talvez possa estar associada à manipulação das mesmas pelos consumidores e funcionários e ou à condição de acondicionamento e locais de estocagem.

$O$ encontro de maior proporção de enteroparasitas na zona norte poderia ser explicado pelo fato de que alguns bairros são desprovidos de saneamento, ou o têm em condições precárias, o que poderia comprometer 0 acondicionamento das hortaliças e o manuseio e distribuição das mesmas. Outros fatores epidemiologicos tais como moscas e a propria água contaminada utilizada na irrigação ${ }^{13}$ podem contribuir fortemente para a contaminação das verduras consumidas cruas.

O encontro de um ovo de Taenia sp. mostra que há possibilidade de se adquirir cisticercose através de hortaliças cruas ou mal cozidas, caso se trate de Taenia solium.

Encontrou-se também um ovo de Trichosomoides crassicauda e outro de Hymenolepis diminuta, ambos parasitas comuns do rato. A presença de enteroparasitas de roedores em hortaliças sugere a contaminação das mesmas por excretas desses animais, potenciais reservatórios da leptospirose cujo agente, a Leptospira, é eliminado pelas fezes e urina e pode sobreviver em ambiente úmido por várias horas.

Por outro lado, quando se examina a água da lavagem de hortaliças, é comum o encontro de amebídeos, flagelados, ovos e larvas de nematódeos de vida livre, muito parecidos com parasitas patogênicos e de difícil identificação, os quais podem confundir o observador $^{78}$.

Comparando os nossos resultados com as observações de Oliveira e Germano ${ }^{14}$, verificou-se coincidência no encontro de ovos de helmintos e cistos de protozoários. Em geral houve um predomínio de ovos de helmintos em relação à freqüência de cistos de protozoários.

Assim, o problema da veiculação dos enteroparasitas em nosso país permanece relevante, como mostram os resultados da pesquisa realizada. O exame de 220 amostras de hortaliças de supermercados sugere a contaminação fecal das verduras pelo manuseio das mesmas ou pelo modo e locais de acondicionamento. Consideramos que os métodos empregados foram satisfatórios para o diagnóstico parasitológico das hortaliças.

\section{AGRADECIMENTOS}

Os autores agradecem a colaboração de Elizabeth Brito da Silva Alves na coleta do material.

\section{SUMMARY}

Parasitological examinations were performed in material derived from 220 vegetables to detect cysts and eggs of intestinal parasites. This material was collected from supermarkets in northern and southern areas and from CEASA (Central Supply Market - 40 vegetables) in Rio de Janetro city. Vegetables proceeding from the northern areas presented a greater degree of contamination mostly of belminth eggs; lettuce was the most contaminated vegetable. The autbors suggest that differences found between the northern and southern areas of the city may be due to either packing or manipulation by shop assistants and consumers.

Key-words: Intestinal parasites. Vegetables. Contamination. 
Silva JP, Marzocbi MCA, Camillo-Coura L, Messias AA, Marques S. Estudo da contaminação por enteroparasitas em bortaliças comercializadas nos supermercados da cidade do Rio de Janeiro. Revista da Sociedade Brasileira de Medicina Tropical 28:237-241, jul-set, 1995.

\section{REFERÊNCIAS BIBLIOGRÁFICAS}

1. Buonomini G, Ricciardi ML, Gozzi E. Sulla resistenza delle cisti di Entamoeba bistolytica in varie condizioni ambientali. Nota 1 - Durante della contaminazioni di piantine di insalata (Lactuca sativa). Giornále di Malattie Infecttive e Parassitarie 10:801-803, 1958.

2. Costa A. Determinação da intensidade de poluição fecal de alface (Lactuca sativa) oferecida ao consumo no Mercado Municipal de Ribeirão Preto, SP. In: Anais da 4a Jornada Farmacêutica p.28-29, 1972.

3. Faust EC, Sawitz W, Tobie J, Odom V, Peres C, Lincicome DR. Comparative efficiency of various technics for the diagnosis of protozoa and helminths in feces. Journal of Parasitology 25:241-162, 1939.

4. Ferrioli Filho F, Barreto MP. Recuperação de cistos de protozoários ovos de helmintos $\mathrm{cm}$ água mediante a ultracentrifugação contínua. Revista Brasileira de Biologia 22:61-64, 1962.

5. Lutz A. Scbistosomum mansoni e a Schistosomose, segundo observações feitas no Brasil. Memórias do Instituto Oswaldo Cruz 11: 127-128, 1919.

6. Marzochi MCA. Estudo dos fatores envolvidos na disseminação dos enteroparasitas. 1.Estudo de poluição por cistos e ovos de enteroparasitas em córregos da cidade de Ribeirão Preto, SP, Brasil. Revista do Instituto de Medicina Tropical de São Paulo 12:249-256, 1970.

7. Marzochi MCA. Estudo dos fatores envolvidos na disseminação dos enteroparasitas. II. Estudo da contaminação de verduras e solo de hortas na cidade de Ribeirão Preto, São Paulo, Brasil. Revista do Instituto de Medicina Tropical de São Paulo 19: 148-155, 1977.

8. Marzochi MCA. Poluição e enteroparasitoses. Ciência e Cultura 29:771-778, 1977.

9. Marzochi MCA, Carvalheiro JR. Estudo dos fatores envolvidos na disseminação dos enteroparasitas. III. Distribuição de algumas enteroparasitoses em dois grupos populacionais da cidade de Ribeirão Preto, SP, Brasil . Revista do Instituto de Medicina Tropical de São Paulo 20:31-35, 1978.

10. Marzochi MCA, Chieffi PP. Estudo dos fatores envolvidos na disseminação dos enteroparasitas. IV. Distribuição do Necator americanus e do Ancylostoma duodenale no Município de Londrina, PR, Brasil. Revista do Instituto de
Medicina Tropical de São Paulo 20:36-40, 1978.

11. Mastrandrea GB, Micarelli A. Ricerca parasitaria nei prodotte vegetalli de alcuni mercati rionale dela cita de Roma. Archevio Italiano de Scienze Mediche Tropicali e di Parassitologia 49:55-59, 1968.

12. Milles RG, Bartlett GL, Kessel JF. The penetration of fruits and vegetables by bacteria and other particulate matter and resistance of bacteria, protozoan cystts and helminths ova to common desinfection methods. American Journal of Hygiene 5:559-579 1925.

13. Neghme A, Silva R, Artigas J. Nuevos aspectos sobre epidemilogia de la amebiase y enteroparasitosis. Revista Chilena de Hygiene y Medicina Preventiva 14: 243-257, 1952.

14. Oliveira CAF, Germano PML. Estudo da ocorrência de enteroparasitas em hortaliças comercializadas na Região Metropolitana de São Paulo - SP, Brasil. I. Pesquisa de helmintos. Revista de Saúde Pública, São Paulo, 26: 283-289, 1992.

15. Page FC. An ilustrated key to Freshewater Biological Association, 34:155. Titus Wilson \& Som. Kendal, 1976.

16. Pattoli $D$, Pain GV. Enteroparasitos de águas de irrigação de hortas que abastecem o Município de São Paulo. Revista Paulista de Medicina 68:241, 1966.

17. Pinheiro MIS, Marzochi MCA, Giugliano R, Giugliano JG. Enteroparasitoses em uma comunidade fechada. I. Estudo do solo como elo de transmissão em um orfanato de Manaus, Am, Brasil.Acta Amazônica 7:503-506, 1977.

18. Scholten T. Soil amebae in Canadá. Community Medicinal Association Journal, 120: 267-268, 1979.

19. Silva JP. Contaminação de Praças no Município do Rio de Janeiro, por ovos de helmintos. Atas da Sociedade de Biologia do Rio de Janeiro 24: 1-2, 1984.

20. Silva JP, Marzochi MC, Leal EC. Avaliação da contaminação experimental de areias de praias por enteroparasitas. Pesquisa de ovos de helmintos. Caderno de Saúde Pública 7:90-99, 1991.

21. Thiatsut P. Action of aqueous solution of iodine on fresh vegetables bad on the intective stages of some common intestinal nematodes. American Journal of Tropical Medicine 10:39-43, 1961. 